\title{
The Attack in Volleyball from the Perspective of Social Network Analysis: Refining Match Analysis through Interconnectivity and Composite of Variables
}

\author{
Joao Bernardo Martins', Jose Afonso', Patrícia Coutinho' ${ }^{1}$, Ricardo Fernandes ${ }^{1,2}$, Isabel Mesquita' \\ Affiliations: 'University of Porto, Faculty of Sport, Centre for Research, Education, Innovation and Intervention in Sport, Porto, Portugal, ${ }^{2}$ University \\ of Porto, Porto Biomechanics Laboratory, Porto, Portugal
}

Correspondence: J.B. Martins, University of Porto, Faculty of Sport, R. Dr. Plácido da Costa 91, 4200-450 Porto, Portugal. E-mail: up201607440@fade.up.pt

\begin{abstract}
This study aimed to develop an instrument for analysing the attack in high-level volleyball considering the refined variables adjacent to the attack action, the interconnection between direct and indirect actions, the impact of the previous action, and the formation of composite variables. The game complexes were approached as interacting subsystems. The primary goal was to understand the influence of game actions adjacent to the attack. Three matches of a National Women's $1^{\text {st }}$ Division 2018/2019 (nine sets, 415 plays) were analysed, considering all game complexes (except attack coverage due to reduced occurrence). An Eigenvector Centrality network with 420 nodes and 7367 edges was created. The networks showed that ideal setting conditions, and strong attacks by the outside and opposite hitters without having received a perfect ball, were central in side-out. In transition, we highlight ideal setting conditions, preferences of the outside hitter, quick attacks in Z4, and high balls in Z2. This study is distinct because it considers different aspects related to the systemic review of the game by using composite variables and the actions prior to the attack. Of these results, we highlight that players attacked with slower tempos for the double action of receive-attack, and these were either preferably directed to the parallel or explored the block. Moreover, for the double defence-attack actions, attackers sought the soft spike in Z2, Z4, and Z8; and when two consecutive individual errors occurred, the players did not err but instead continued to attack to force the opponent's error.
\end{abstract}

Keywords: performance analysis, game analysis, social network analysis, eigenvector centrality, attack, volleyball

@MJSSMontenegro

ATTACK IN VOLLEYBALL THROUGH INTERCONNECTIVITY

http://mjssm.me/?sekcija=article\&artid=212

Cite this article: Martins, J.B., Afonso, J., Coutinho, P., Fernandes, R., \& Mesquita, I. (2021). The Attack in Volleyball from the Perspective of Social Network Analysis: Refining Match Analysis through Interconnectivity and Composite of Variables. Montenegrin Journal of Sports Science and Medicine, 10 (1), 45-54. doi: 10.26773/mjssm.210307

\section{Introduction}

The study and development of team sports can be conceptualized at three levels with performance analysis as an umbrella concept, match analysis as a sub-genre within performance, and Social Network Analysis as a specific tool for conducting match analysis. Performance analysis refers to the interpretation of different performance indicators for the optimization of the training process and matches (Hughes, 2004). One of 
its primary objectives is to provide feedback to athletes and coaches to support decision making (Hodges \& Franks, 2008). Match analysis, the process of recording individual game actions within a play context (Hughes \& Franks, 2008), is one possible application of performance analysis. Match analysis has contributed positively to volleyball research on the influence of reception quality, attack tempo and block type on attack efficacy (Costa, Afonso, Barbosa, Coutinho, \& Mesquita, 2014); on the performance links between game actions and the final ranking in the league (Conejero, Claver, González-Silva, Fernández-Echeverría, \& Moreno, 2017); and on the creation of references to understand team performance in certain game actions by means of a longitudinal study (Drikos \& Tsoukos, 2018).

Social Network Analysis has established itself as a powerful tool for match analysis, particularly when focusing on behaviour and the relationships between the players involved in the network (captured by nodes and connected by edges; Borgatti, 2005; Wäsche, Dickson, Woll, \& Brandes, 2017). Studies have mostly focused on match analysis with the nodes centred on the players (Ribeiro, Silva, Duarte, Davids, \& Garganta, 2017). Thus far, the most common measure has been degree centrality (e.g., Gama et al., 2014; McLean, Salmon, Gorman, Stevens, \& Solomon, 2018), which calculates the number of direct connections between nodes (Borgatti, 2005). However, recent research in volleyball (Laporta, Afonso, and Mesquita, 2018a; 2018b; Laporta, Afonso, Valongo, and Mesquita, 2019) has applied Eigenvector Centrality, which considers the value of a node as the weighted sum of both direct and indirect connections (Bonacich, 2007). Moreover, such studies have begun to consider game actions, and not only players, as nodes (e.g., Hurst et al., 2016; Laporta et al., 2019).

These studies made significant contributions to the literature, but most had limitations concerning the way in which attack actions were analysed. These limitations included a limited consideration of game actions without the ball, using tools with relatively limited levels of efficacy and, most notably, the analysis of each action without considering the outcome of previous attack actions. We aim to overcome these limitations to give a greater systematic overview of the game. Moreover, we also aim to address the limitation of conducting match analysis via interconnectivity and compositive variables. For match analysis to be representative of the game, interactions between current and previous actions, and the effects of prior efficacy on current efficacy, should be considered.

In sum, the overarching goal of the current study was to develop a more comprehensive analysis of volleyball game actions. We aimed to meet this goal by testing a more refined instrument for analysing attack actions. This instrument considers the interconnection between direct and indirect actions, the influence of the previous action, and the formation of composite variables. Thus, because it was designed to consider the dynamics and complexity of the game, we anticipated this instrument would represent a fundamental tool aligned with the potential of Social Network Analysis.

\section{Methods \\ Sample}

We analysed three matches, corresponding to nine sets and 415 plays, from a National Women's 1st Division (2018/2019). All complexes were analysed. More specifically, we analysed the node corresponding to the attack action and its relations with other nodes (other game actions).

\section{Variables}

The variables were classified as either simple or composite (see Table 1). Volleyball is structured in seven interdependent game complexes with distinct game flow characteristics (Loureiro et al., 2017; Hurst et al., 2016): complex 0 (K0) or serve, Complex I (KI) or side-out, Complex II (KII) or side-out transition, Complex III (KIII) or transition, Complex IV (KIV) or attack coverage, Complex V (KV) or freeball, and Complex VI (KVI) or downball. We chose not to analyse KIV because of its low occurrence, with only $3.89 \%$ of ball possession in men and $4.1 \%$ in women (Laporta, 2014).

The simple variables analysed were server starting position (Data Volley, 2018; Fernández-Echeverría et al., 2017), type of serve (Afonso, Esteves, Araújo, Thomas, \& Mesquita, 2012), serve relationship with the positioning of the screening, serve efficacy, first contact zone, type of reception contact, the function of the player who received or attacked (outside hitter $(\mathrm{OH})$, libero (LB), middle-blocker (MB), opposite (OPP), setter (ST)) (adapted from Afonso et al., 2012), ideal vs non-ideal setting conditions (Hurst et al., 2016; Laporta et al., 2018b), availability of the middle-blocker (adapted from Afonso, Mesquita, Marcelino, \& Silva, 2010), and the combination of attack with tempo (adapted from Afonso et al., 2010; Data Volley, 2018).

We also studied where the attacker establishes contact with the ball (the need to clarify the various attack tempos across the nine zones resulted in 20 combinations), attack trajectories (Data Volley, 2018), type of attack (based on the position of the attacker and attack efficacy; Data Volley, 2018), the behaviour of the block (e.g., its starting points; adapted from Afonso, Laporta, and Mesquita, 2017), behaviour prior to the setter (adapted from Afonso \& Mesquita, 2011), block opposition being without blocks, and efficacy of the block (Data Volley, 2018). Composite variables were also coded: attack without/ after receiving, attack after two consecutive errors, and attack after defence/undefended attack.

\section{Data collection, procedures and reliability}

First, a spreadsheet was built in Microsoft Excel 2017 with macro buttons to catalogue the necessary codes into the appropriate cells. The data collection procedures were then conducted, and intra-observer reliability evaluated using $10 \%$ of the total sample (cf. Fleiss, Levin, \& Paik, 2013). For intra-observation reliability, Cohen's Kappa values ranged from .959 to 999 . For inter-observation reliability, these values ranged from .774 to .997 . Thus, all variables were greater than the threshold of 0.75 proposed by Tabachnick and Fidell (2007).

Next, data were analysed using SPSS for Windows (version $\left.25, \mathrm{IBM}^{\oplus}, \mathrm{USA}\right)$, which included a verification of data quality followed by descriptive analysis and the production of cross tables. The software Gephi@ was used to calculate the connections and their weights using Eigenvector Centrality. Node sizes were manipulated using the intrinsic units given by the software, set to vary between 300 and 1500 to ensure proper visual contrast.

\section{Results}

A global network of intra- and inter-complex interactions was established using Eigenvector Centrality to provide a map of interactions (Figure 1). To create an interactive network, the complexes were separated by colour: K0 (yellow), KI (red), KII (grey), KIII (green), KV (purple) and KVI (pink). 


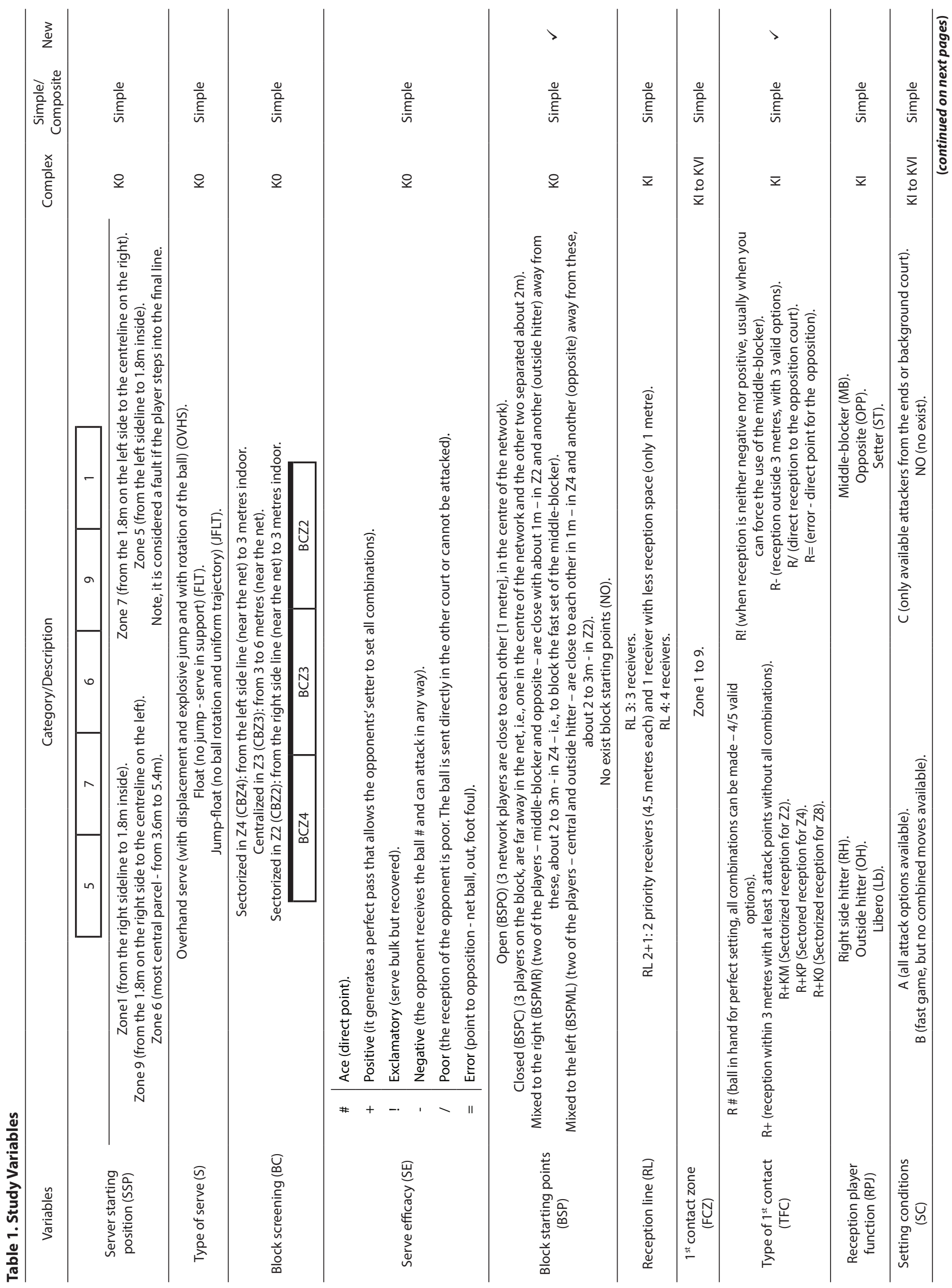




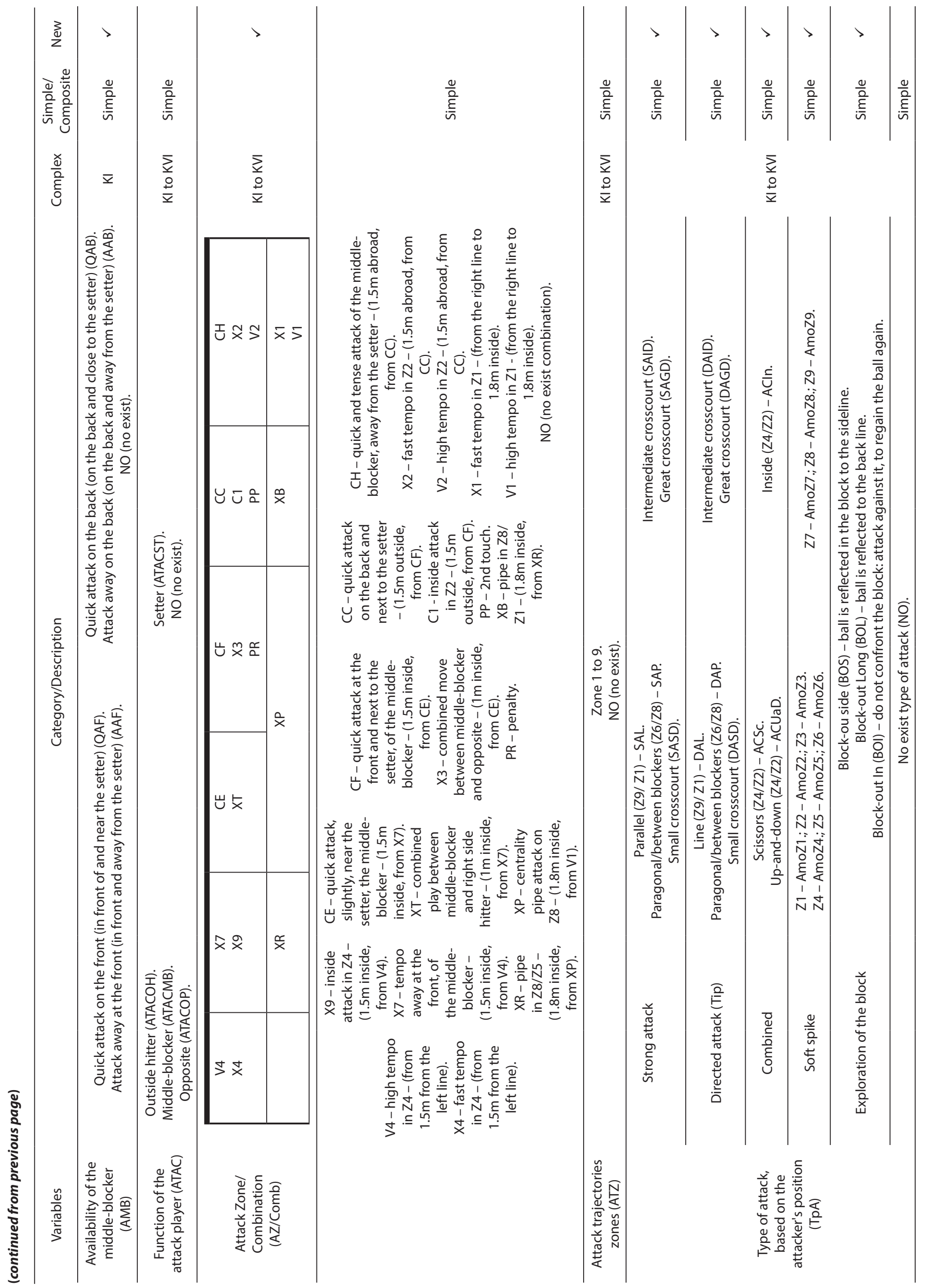




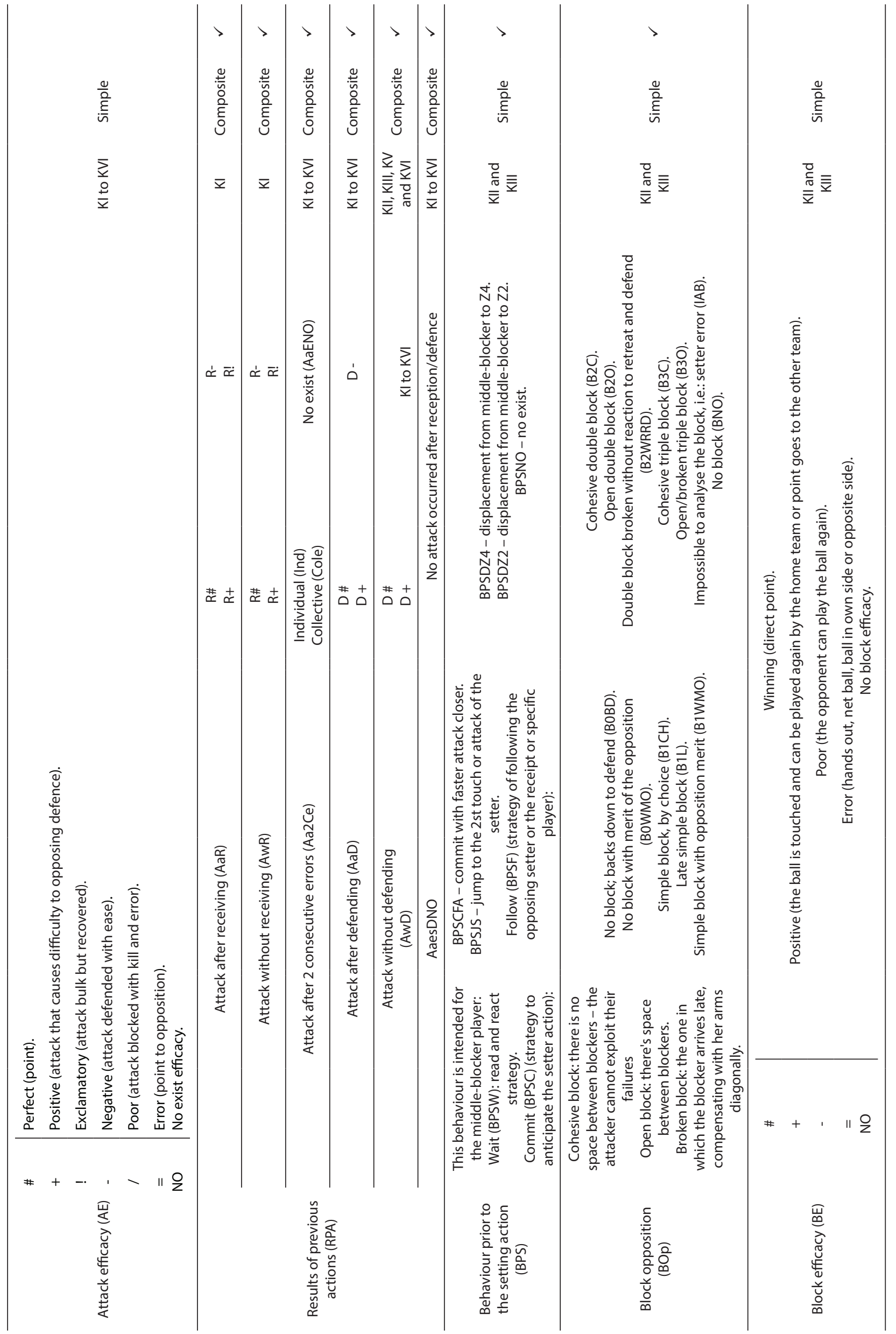




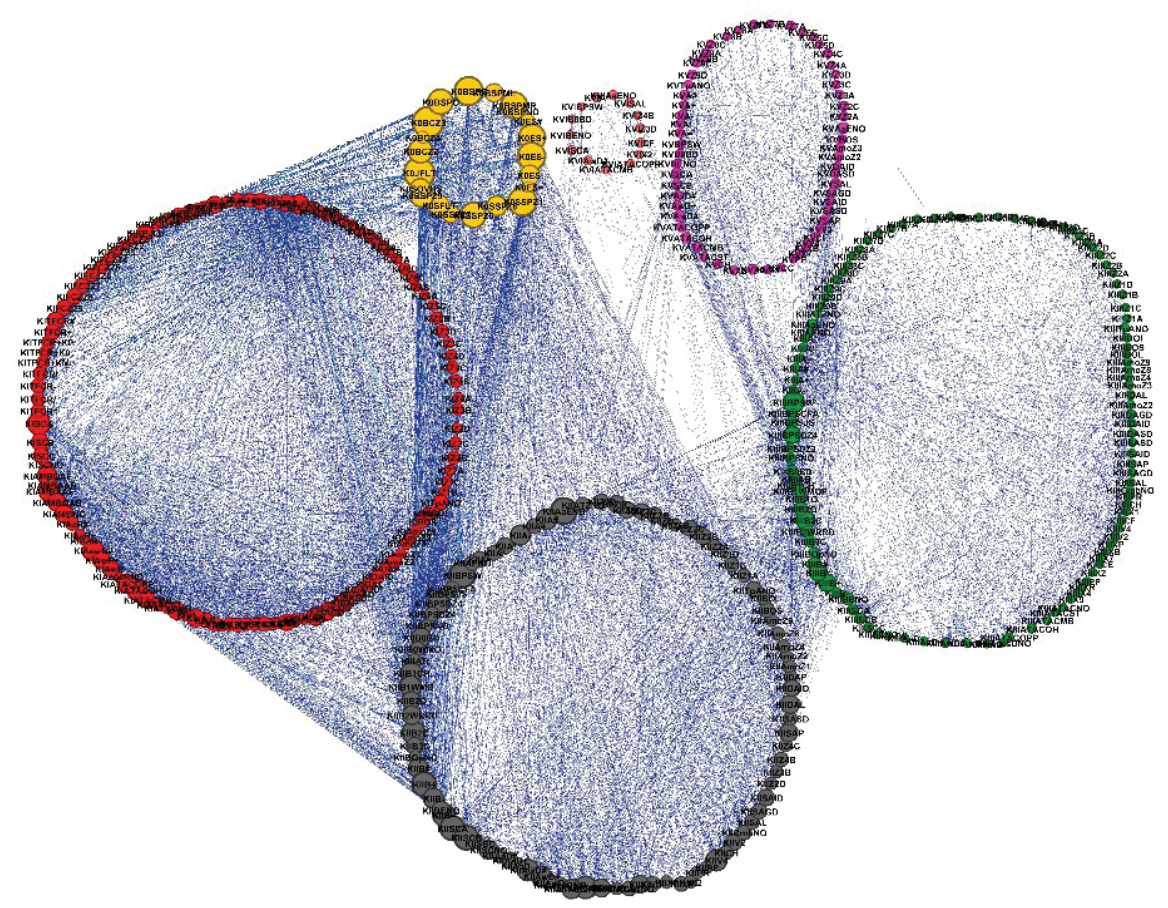

FIGURE 1. Network of the six complexes, with Eigenvector Centrality. Terminology: On each node, the codes are represented by the name of the complex, followed by the variable and its category. For example, KIIATACOH indicates that the action occurred in complex II, the variable in question was the function of the attacker, in this case, the outside hitter. The codes for the different variables: SSP - server starting position; S - type of serve; $\mathrm{BC}$ - screening block; BSP - block starting point; SE - serve efficacy; RL - reception line; RJP - player's reception function; FCZ - first contact zone; TFC - type of first contact; SC - setting conditions; AMB - availability of the middle-blocker; AAEWEX - attack after or without receive/defend; ATAC - attacker function; CMB - combination of attack; ATZ - attack trajectory zone; TpA - type of attack; AAE - attack after error; AE - attack efficacy; BPS - behaviour prior to the setting action; BOp - block opposition; BE - block efficacy. The EC values corresponding to each of the variables per complex are expressed in Table 2. In the K0, we highlight the values of; the jump-float serve, of serving from Z1, of the block screening in Z3, and serve efficacy being negative or positive. In KI, the most used was ideal setting conditions compared to the non-ideal. The most requested player in side-out was the $\mathrm{OH}$, followed by OPP and MB. Concerning the attack, mostly it was without receiving but with the perfect ball followed by without receiving but with the positive ball. In situations in which the attacker received a perfect or positive ball and then attacked, the attackers sought to attack directed to the parallel, soft spike in Z9, or explored the block. Conversely, the attack tempo was fast on the Z4, slow on Z2 and the MB to attack CF and $\mathrm{CH}$. In turn, the type of attack was either a strong attack on the parallel, a paragonal-directed attack, a great crosscourt or a crosscourt intermediate attack with a great efficacy of attack. As for the attack after two collective errors, the players sought the most controlled attack on the small crosscourt and the soft spike (Z3 and Z2).

The EC values for each of the variables per complex are presented in Table 2. In K0, we highlight the values for several variables: the jump-float serve, serving from Z1, the block screening in $Z 3$, and serve efficacy being negative or positive. In KI, ideal setting conditions were more often used than non-ideal setting conditions. The most requested player in side-out was the $\mathrm{OH}$, followed by OPP and MB. Most attacks happened without receiving and with a perfect ball. The second most common type of attacks happened without receiving and with a positive ball. In situations in which the attacker received a perfect or positive ball and then attacked, the attack was directed to the parallel, there was a soft spike in Z9, or the block was explored. The attack tempo was fast on the Z4, slow on $\mathrm{Z} 2$, and the $\mathrm{MB}$ tended to attack $\mathrm{CF}$ and $\mathrm{CH}$. In turn, the type of attack was either a strong attack on the parallel, a paragon-directed attack, a great crosscourt, or a crosscourt intermediate attack with a high attack efficiency. In the case of the attack after two collective errors, the players sought the most controlled attack on the small crosscourt and the soft spike (Z3 and Z2).

In KII, the block was characterized by a wait, due to the conditions of the setter (mostly ideal), and the block opposition was double cohesive or individual. The most requested player was the $\mathrm{OH}$. The most used attack tempos were the quick ball (in Z4), the high ball (in Z2), and CF from MB. As for the type of attack, it was used in the directed attack in line, as well as the strong attack in paragonal/between blockers and the strong attack in intermediate crosscourt. When players attacked after a positive defence, they looked for the soft spike in zones 2, 8, and 4. In KIII, the behaviour prior to the setting action was often waiting or to accompany to Z4, due to the higher occurrence of SCB followed by SCA and SCC, with block opposition being, mostly, double cohesive. The most requested attackers were the extremities (OH and $\mathrm{OPP})$. The trajectories most performed by these attackers were the strong attack on the parallel, on the great crosscourt, and an attack tempo with the high ball. In $\mathrm{KV}$, the ideal setting conditions predominated, followed by many attacks not preceded by perfect defences, and the most requested player was $\mathrm{OH}$ (who always had quick balls and sought to attack the parallel). The behaviour of the opposition block was always to wait. Finally, in KVI, due to its low occurrence (only twice), the ideal setting conditions and the attack of the MB were highlighted.

\section{Discussion}

In Social Network Analysis, interaction networks analyse the degree of connection and specificity in the different phases of a game, thus helping to identify the most influential critical 
actions in the flow of the game (Wäsche et al., 2017). Eigenvector Centrality weight both direct and indirect connections between nodes (Laporta et al., 2018a; 2018b). The current study aimed to create a more refined instrument for studying the attack in volleyball. This instrument considers the interconnection between direct and indirect action, the impact of the previous action, the use of composite variables, and adding a finer-graining filter to the analysis (i.e., by using specific variables surrounding the attack). Our data illustrate the complex dynamics of the game actions within each phase of the game and highlight the decisive role of each node, which aids in providing a more detailed perspective of the phenomena that occur within the interactive network.

Our results regarding specific variables are consistent with the literature (Costa et al., 2014; Laporta et al., 2018b) in that they show the most requested player in the attack was the outside hitter (followed by the opposite) and that the tempo of the attack included quick ball attacks at $\mathrm{Z} 4$ and high ball at $\mathrm{Z} 2$

Table 2. Eigenvector Centrality values for Complex

\begin{tabular}{|c|c|c|}
\hline Complex & Variable & Eigenvector Centrality values \\
\hline \multirow{5}{*}{ K0 } & Server starting position (SSP) & Z1 (0.83); Z5 (0.69); Z6 (0.60); Z7 (0.49); Z9 (0.60) \\
\hline & Type of serve (S) & OVHS (0.44); FLT (0.58); JFLT (0.85) \\
\hline & Block screening (BC) & $\mathrm{Z2}(0.62) ; \mathrm{Z3}(0.87) ; \mathrm{Z4}(0.18)$ \\
\hline & Block starting points (BSP) & BSPO (0.67); BSPC (0.78); BPSMR (0.72); BSPML (0.46); BSPNO (0.21) \\
\hline & Serve efficacy (SE) & $\mathrm{S} \#(0.20) ; \mathrm{S}+(0.73) ; \mathrm{S!}(0.53) ; \mathrm{S}-(0.77) ; \mathrm{S}=(0.13)$ \\
\hline \multirow{14}{*}{$\mathrm{KI}$} & Reception line (RL) & $3(0.29) ; 2+1(0.14) ; 4(0.11)$ \\
\hline & 1st contact zone (FCZ) & Z1 (0.20); Z2 (0.15); Z3 (0.08); Z4 (0.10); Z5 (0.21); Z6 (0.25); Z7 (0.25); Z8 (0.25); Z9 (0.25) \\
\hline & Type of 1st contact (TFC) & $\begin{array}{l}\mathrm{R} \#(0.32) ; \mathrm{R}+(0.27) ; \mathrm{R}+\mathrm{KM}(0.20) ; \mathrm{R}+\mathrm{KP}(0.20) ; \mathrm{R}+\mathrm{K} 0 \text { (0.19); R! (0.26); R- }(0.24) ; \mathrm{R} /(0.20) ; \mathrm{R}= \\
(0.19)\end{array}$ \\
\hline & Reception player function (RPJ) & $\mathrm{OH}(0.25) ; \mathrm{RH}(0.26) ; \mathrm{Lb}(0.29) ; \mathrm{MB}(0.14) ; \mathrm{OPP}(0.09)$ \\
\hline & Setting conditions (SC) & $\mathrm{A}(0.77) ; \mathrm{B}(0.55) ; \mathrm{C}(0.47) ; \mathrm{NO}(0.07)$ \\
\hline & Availability of the middle-blocker (AMB) & QAF (0.70); AAF (0.69); QAB (0.61); AAB (0.46); NO (0.54) \\
\hline & Function of the attack player (ATAC) & $\mathrm{OH}(0.68) ; \mathrm{MB}(0.57) ; \mathrm{OPP}(0.64) ; \mathrm{ST}(0.33) ; \mathrm{NO}(0.13)$ \\
\hline & Attack without receiving (AwR) & $\mathrm{R \#}(0.71) ; \mathrm{R}+(0.60) ; \mathrm{R}-(0.53)$ \\
\hline & Attack after receiving $(\mathrm{AaR})$ & $\mathrm{R} \#(0.34) ; \mathrm{R}+(0.34) ; \mathrm{R}-(0.30)$ \\
\hline & Attack after 2 consecutive errors ( $\mathrm{Aa} 2 \mathrm{E})$ & Colec (0.35); NO (0.80) \\
\hline & Attack Zone/Combination (Cmb) & $\begin{array}{l}\text { XP (0.34); V2 (0.49); X2 (0.34); PP (0.29); CF (0.37); CE (0.25); X9 (0.29); X7 (0.30);V4 (0.62); X4 } \\
(0.53) ; X 1(0.13) ; C C(0.22) ; X R(0.31) ; C H(0.39) ; V 1(0.30) ; \text { N0 }(0.12)\end{array}$ \\
\hline & Attack trajectories zones (ATZ) & 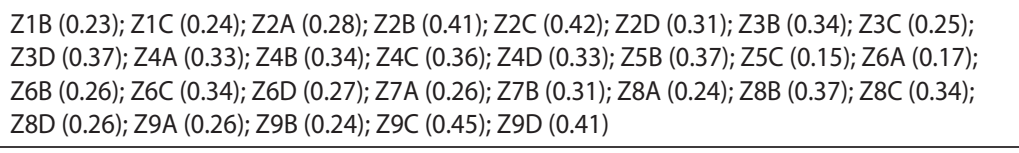 \\
\hline & Type of attack (TpA) & $\begin{array}{l}\text { SAL (0.52); SAP (0.57); SASD (0.30); SAID (0.48); SAGD (0.49); DAL (0.33); DAP (0.49); DASD } \\
\text { (0.36); DAID (0.46); AmoZ2 (0.33); AmoZ3 (0.36); AmoZ4 (0.35); AmoZ8 (0.26); AmoZ9 (0.22); } \\
\text { BOS (0.34); BOI (0.30); BOL (0.30); NO (0.32) }\end{array}$ \\
\hline & Attack efficacy (AE) & $\mathrm{A} \#(0.66) ; \mathrm{A}+(0.52) ; \mathrm{A} /(0.6447 \mathrm{~A}-(0.64) ; \mathrm{A} !(0.29) ; \mathrm{A}=(0.51) ; \mathrm{NO}(0.18)$ \\
\hline \multirow{12}{*}{ KII } & Behaviour prior to the setting action (BPS) & BPSW (1); BPSCFA (0.48); BPSJS (0.28); BPSDZ4 (0.76); BPSDZ2 (0.57); BPSNO (0.13) \\
\hline & Block opposition (B) & $\begin{array}{l}\text { BOBD (0.69); BOWMO (0.30); B1CH (0.78); B1WMO (0.76); B2C (0.89); B2O (0.70); B2WRRD } \\
(0.53) ; \mathrm{B} 3 \mathrm{C}(0.61) ; \mathrm{IAB}(0.24) ; \mathrm{OpBNO}(0.13)\end{array}$ \\
\hline & Block efficacy (BE) & $\mathrm{B} \#(0.64) ; \mathrm{B}+(0.95) ; \mathrm{B}-(0.89) ; \mathrm{B}=(0.86) ; \mathrm{EBNO}(0.46)$ \\
\hline & Setting conditions (SC) & $\mathrm{A}(0.75) ; \mathrm{B}(0.75) ; \mathrm{C}(0.35) ; \mathrm{NO}(0.43)$ \\
\hline & Function of the attack player (ATAC) & $\mathrm{OH}(0.58) ; \mathrm{MB}(0.47) ; \mathrm{OPP}(0.49) ; \mathrm{ST}(0.25) ; \mathrm{NO}(0.24)$ \\
\hline & Attack without defending (AwD) & $\mathrm{D} \#(0.59) ; \mathrm{D}+(0.54) ; \mathrm{D}-(0.24)$ \\
\hline & Attack after defending (AaD) & $\mathrm{D \#}(0.21) ; \mathrm{D}+(0.31) ; \mathrm{D}-(0.14)$ \\
\hline & Attack after 2 consecutive errors (Aa2E) & NO $(0.69)$ \\
\hline & Attack Zone/Combination (Cmb) & $\begin{array}{l}\mathrm{XP}(0.27) ; \mathrm{V} 2(0.40) ; \mathrm{X} 2(0.15) ; \mathrm{PP}(0.25) ; \mathrm{CF}(0.33) ; \mathrm{X} 7(0.26) ; \mathrm{V} 4(0.50) ; \mathrm{X} 4(0.46) ; \mathrm{PR}(0.19) ; \mathrm{CH} \\
(0.22) ; \mathrm{NO}(0.23)\end{array}$ \\
\hline & Attack trajectories zones (ATZ) & $\begin{array}{l}\text { Z1A (0.20); Z1C (0.28); Z1D (0.11); Z2A (0.15); Z2B (0.34); Z2C (0.32); Z2D (0.23); Z3B (0.20); } \\
\text { Z4B (0.29); Z4C (0.25); Z6B (0.18); Z6C (0.24); Z7B (0.29); Z7C (0.31); Z8D (0.34); Z9C(0.35); Z9D } \\
(0.26) ; \mathrm{NO}(0.23)\end{array}$ \\
\hline & Type of attack (TpA) & $\begin{array}{l}\text { SAL (0.34); SALP (0.39); SASD (0.24); SAID (0.33); SAGD (0.32); DAL (0.40); DAP (0.27); DAID } \\
\text { (0.33); AmoZ1 (0.15); AmoZ2 (0.28); AmoZ4 (0.20); AmoZ8 (0.22); AmoZ9 (0.19); BOS (0.29); } \\
\text { BOI (0.24); NO (0.30) }\end{array}$ \\
\hline & Attack efficacy (AE) & $\mathrm{A} \#(0.52) ; \mathrm{A}+(0.38) ; \mathrm{A} /(0.29) ; \mathrm{A}-(0.45) ; \mathrm{A} !(0.28) ; \mathrm{A}=(0.33) ; \mathrm{NO}(0.21)$ \\
\hline
\end{tabular}


(continued from previous page)

\begin{tabular}{|c|c|c|}
\hline Complex & Variable & Eigenvector Centrality values \\
\hline \multirow{12}{*}{ KIII } & Behaviour prior to the setting action (BPS) & BPSW (0.57); BPSCFA (0.13); BPSDZ4 (0.14); BPSDZ2 (0.33); BPSNO (0.15); \\
\hline & Block opposition (B) & $\begin{array}{l}\text { BOBD (0.29); B1CH (0.27); B1O (0.11); B1WMO (0.32); B2C (0.50); B2O (0.30); B2WRRD }(0.21) ; \\
\text { B3C (0.20); IAB (0.01); OpBNO }(0.05)\end{array}$ \\
\hline & Block efficacy (BE) & $\mathrm{B \#}(0.24) ; \mathrm{B}+(0.41) ; \mathrm{B}-(0.37) ; \mathrm{B}=(0.44) ; \mathrm{EBNO}(0.21)$ \\
\hline & Setting conditions (SC) & A (0.13); B (0.13); C (0.08); NO (0.06) \\
\hline & Function of the attack player (ATAC) & $\mathrm{OH}(0.07) ; \mathrm{MB}(0.03) ; \mathrm{OPP}(0.06) ; \mathrm{ST}(0.01) ; \mathrm{NO}(0.006)$ \\
\hline & Attack without defending (AwD) & $\mathrm{D \#}(0.06) ; \mathrm{D}+(0.05) ; \mathrm{D}-(0.03)$ \\
\hline & Attack after defending $(\mathrm{AaD})$ & D\# (0.02); D+ (0.009); D- (0.01) \\
\hline & Attack after 2 consecutive errors (Aa2E) & NO (0.09) \\
\hline & Attack Zone/Combination (Cmb) & $\begin{array}{l}\text { XP (0.03); V2 (0.05); X2 (0.02); PP (0.02); CF (0.01); CE (0.01); X9 (0.02); X7 (0.02); V4 (0.05); X4 } \\
(0.03) ; \mathrm{PR}(0.01) ; \mathrm{X} 1(0.01) ; \mathrm{XB}(0.01) ; \mathrm{XR}(0.01) ; \mathrm{CH}(0.01) ; \mathrm{NO}(0.007)\end{array}$ \\
\hline & Attack trajectories zones (ATZ) & 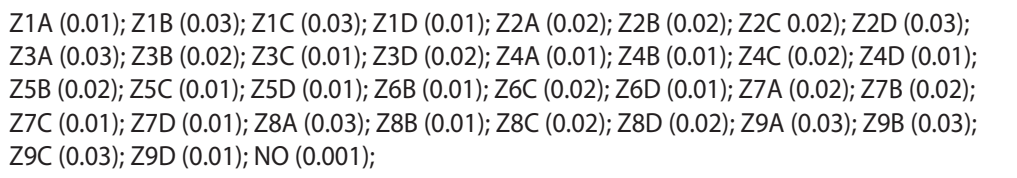 \\
\hline & Type of attack (TpA) & $\begin{array}{l}\text { SAL (0.04); SAP (0.03); SASD (0.01); SAID (0.03); SAGD (0.04); DAL (0.03); DASD (0.03); DAID } \\
(0.02) ; \operatorname{DAGD~(0.01);~AmoZ2~(0.03);~AmoZ3~(0.03);~AmoZ4~(0.01);~AmoZ8~(0.01);~AmoZ9~(0.02);~} \\
\text { BOS (0.02); BOI (0.01); BOL (0.01); NO (0.02) }\end{array}$ \\
\hline & Attack efficacy (AE) & A\# (0.07); A+ (0.05); A/ (0.02); A- (0.04); A= (0.04); NO (0.007) \\
\hline \multirow{12}{*}{ KV } & Behaviour prior to the setting action (BPS) & BPSW (0.14) \\
\hline & Block opposition (B) & $\mathrm{BOBD}(0.13)$ \\
\hline & Block efficacy (BE) & NO (0.11) \\
\hline & Setting conditions (SC) & $\mathrm{A}(0.19) ; \mathrm{B}(0.07)$ \\
\hline & Function of the attack player (ATAC) & $\mathrm{OH}(0.15) ; \mathrm{MB}(0.11) ; \mathrm{OPP}(0.10) ; \mathrm{ST}(0.04)$ \\
\hline & Attack without defending (AwD) & $\mathrm{D \#}(0.18) ; \mathrm{D}+(0.06)$ \\
\hline & Attack after defending (AaD) & D\# $(0.03)$ \\
\hline & Attack after 2 consecutive errors (Aa2E) & $\mathrm{NO}(0.17)$ \\
\hline & Attack Zone/Combination (Cmb) & $\begin{array}{l}\text { CC (0.04); CF (0.08); PP (0.04);XB (0.04);X7 (0.04);X9 (0.03);X4 (0.11);V4 (0.09); V2 (0.05);X2 } \\
(0.12) ; C H(0.05)\end{array}$ \\
\hline & Attack trajectories zones (ATZ) & 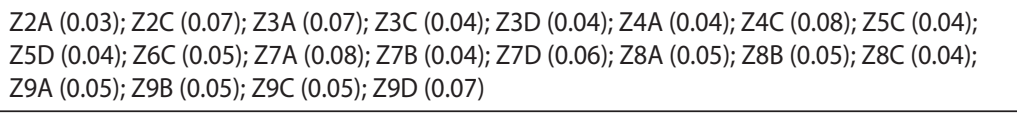 \\
\hline & Type of attack (TpA) & $\begin{array}{l}\text { SAL (0.13); DASD (0.04); BOS (0.04); SAGD (0.08); SAP (0.09); SASD (0.08); SAID (0.05); DAID } \\
(0.07) ; \text { AmoZ2 (0.03); AmoZ3 (0.06); NO (0.04) }\end{array}$ \\
\hline & Attack efficacy (AE) & A\# (0.12); $A+(0.09) ; A /(0.06) ; A-(0.07) ; A=(0.05)$ \\
\hline \multirow{11}{*}{$\mathrm{KVI}$} & Behaviour prior to the setting action (BPS) & BPSW (0.03) \\
\hline & Block opposition (B) & BOBD (0.05) \\
\hline & Block efficacy (BE) & $\mathrm{NO}(0.04)$ \\
\hline & Setting conditions (SC) & $A(0.04)$ \\
\hline & Function of the attack player (ATAC) & MB (0.03); OPP (0.03) \\
\hline & Attack without defending (AwD) & $\mathrm{D \#}(0.03)$ \\
\hline & Attack after 2 consecutive errors ( $\mathrm{Aa} 2 \mathrm{E}$ ) & NO $(0.03)$ \\
\hline & Attack Zone/Combination (Cmb) & CF $(0.03) ; X 2(0.03)$ \\
\hline & Attack trajectories zones (ATZ) & Z3D (0.03); Z4D (0.03) \\
\hline & Type of attack (TpA) & SAL (0.03) \\
\hline & Attack efficacy (AE) & A- $(0.03)$ \\
\hline
\end{tabular}

(perhaps due to the characteristics of the players; Marcelino, Afonso, Moraes, \& Mesquita, 2014). Concerning the type of attack, it is worth noting the strong attack on the paragonal and parallel, the strong attack on the crosscourt (great and intermediate), the attack directed to the parallel and exploration of the block (side and long) because of the frequency of the block playing on wait and presenting between double and late cohesive or on setting merits. However, our results indicated that most of the game takes place between ideal setting conditions (i.e., A and B), which contradicts some previous research 
(Laporta et al., 2018b).

This study highlights the importance of conducting research using more refined variables (Laporta et al., 2019), with better definitions and categories; by using composite variables, thus considering interconnections between actions (direct and indirect) and the impact of the previous actions, it respects to a much greater extent the dynamic and complex systematic review of the game. The refinement of variables is fundamental to understanding the strength between nodes. In this study, the composite variables do not fragment the game and highlight the edges of the network (both in its direction and in its weight). Hence, it was demonstrated that coupled actions (e.g., receive-attack and defend-attack) statistically influence the setters' choices. Here, Eigenvector values reflected a centrality for the slowest attack tempos and trajectories attempting strong attacks in the parallel, soft spikes closer to the net, or exploration of the block (Afonso et al., 2012; Marcellin et al., 2014). It should be noted that seven new variables were created in this study.

The edges of our network clearly showed that when an attacker commits two consecutive attacking errors, they tried not to commit unforced errors in the third attempt, decreasing the assumed risk and allowing the continuity of the game. Moreover, our results revealed ideal setting conditions in KIII (SCB and SCA) as well as quick attack tempos. This finding directly contradicts Laporta et al. (2018b), who referred to non-ideal setting conditions (B and C) in KIII. Thus, our study adjusts to the idea of Marcelino et al. (2014) in which the strike depends on the interaction of several tactical-technical indicators that change the strategies of the teams, providing a systemic understanding of the game.

The large number of variables resulted in a very extensive instrument. Consequently, we will take the following steps for refinement. Firstly, we will aggregate the 36 subcategories for the attack trajectory zone (e.g., instead of Z9A-Z9D, assume solely as Z9) into nine variables. Second, the classification of the reception in KI will be reduced from nine categories to six. Third, when classifying the quality of the first touch, we found there was a direct relationship with the setting conditions (A, B or $\mathrm{C})$, which in our view means it is possible to use only the classification of the setting conditions. Fourth, we will combine KVI with KV due to the rare occurrence of the first complex (twice). Finally, we will eliminate the availability variable of the $\mathrm{MB}$ in $\mathrm{KI}$ because it will have little influence on the attack.

This study has demonstrated that playing patterns are diverse and that play occurs in ideal setting conditions ( $\mathrm{B}$ and A) in most complexes, which contradicts some of the results of Laporta et al. (2018b). Studies of this nature have practical implications for coaches, who should consider training in both ideal and non-ideal setting conditions and diversify attack patterns under various conditions. A substantial intraand inter-complex relationship, which highlights the dynamics and complexity of the game actions, was also identified. Both KI and KII shared ideal setting conditions, outside hitter preference and parallel attack. For the KI-KII and KII-KIII interconnection, the behaviour of the block occurs most centrally on a waiting strategy and the attack tempo is quicker at one edge than at the other. This complex correlation is crucial for coaches to understand because it allows them to promote game scenarios based on previous actions or complexes (Paulo et al., 2018). This instrument has the potential to promote the use of Social Network Analysis in match analysis because it allows for a greater reading of the complexity and dynamics of the game (Passos et al., 2011; Ribeiro et al., 2017; Sasaki, Yamamoto, Miyao, Katsuta, \& Kono, 2017), based on its systemic review. As for avenues to explore in future studies, Social Network Analysis and Eigenvector Centrality should be incorporated into research that addresses contextual variables (punctual difference, set/game moment and intra- and inter-set relationships).

In conclusion, the present study makes several significant contributions to volleyball research. It offers a more refined instrument than currently available in the literature, takes a more specific approach to attack variables, reinforces the importance of considering adjacent variables, and highlights the relevance of indirect connections. Hence, composite variables, interconnections between actions (direct and indirect), and the impact of the previous action are variables that consider the game flow and its interconnectivity. It is clear from the results that this instrument has the potential to advance both volleyball and the construction of instruments in other team sports. Finally, the study demonstrates that Social Network Analysis is a crucial tool for understanding the systemic and complex nature of the game.

\section{References}

Afonso, J., \& Mesquita, I. (2011). Determinants of block cohesiveness and attack efficacy in high-level women's volleyball. European Journal of Sport Science, 11, 69-75. doi: 10.1080/17461391.2010.487114

Afonso, J., Esteves, F., Araújo, R., Thomas, L., \& Mesquita, I. (2012). Tactical determinants of setting zone in elite men's volleyball. Journal of Sports Science \& Medicine, 11(1), 64-70.

Afonso, J., Laporta, L., \& Mesquita, I. (2017). A importância de diferenciar o KII do KIII no voleibol feminino de alto nível. Revista Portuguesa de Ciências do Desporto, 140-147. doi: 10.5628/rpcd.17.S1A.140

Afonso, J., Mesquita, I., Marcelino, J., \& Silva, J. (2010). Analysis of the setter's tactical action in high-performance women's volleyball. Kinesiology, 42(1), 82-89.

Bonacich, P. (2007). Some unique properties of eigenvector centrality. Social Networks, 29(4), 555-564.

Borgatti, S. (2005). Centrality and network flow. Social Networks, 27, 55-71. doi: 10.1016/j.socnet.2004.11.008

Conejero, M., Claver, F., González-Silva, J., FernándezEcheverría, C., \& Moreno, M. (2017). Analysis of performance in game actions in volleyball, according to the classification. Revista Portuguesa de Ciências do Desporto, 17, 196-204. doi: 10.5628/rpcd.17.S1A.196

Costa, G., Afonso, J., Barbosa, R., Coutinho, P., \& Mesquita, I. (2014). Predictors of attack efficacy and attack type in high-level Brazilian women's volleyball. Kinesiology, 46, 242-248.

Drikos, S., \& Tsoukos, A. (2018). Data benchmarking through a longitudinal study in high-level men's volleyball. International Journal of Performance Analysis in Sport, 18(3), 470-480. doi: 10.1080/24748668.2018.1493319

Fernández-Echeverría, C., Mesquita, I., González-Silva, J., Claver, F., \& Perla Moreno, M. (2017). Match analysis within the coaching process: A critical tool to improve coach efficacy. International Journal of Performance Analysis in Sport, 17(1-2), 149-163. doi: 
$10.1080 / 24748668.2017 .1304073$

Fleiss, J. Levin, B., \& Paik, M. (2013). Statistical methods for rates and proportions. John Willey \& Sons.

Gama, J., Passos, P., Davids, K., Relvas, H., Ribeiro, J., Vaz, V., \& Dias, G. (2014). Network analysis and intrateam activity in attacking phases of professional football. International Journal of Performance Analysis in Sport, 14(3), 692-708. doi: 10.1080/24748668.2014.11868752

Hodges, N., \& Franks, I. (2008). The provision of information. In M. D. Hughes, and I. M. Franks (Eds.), Essentials of performance analysis: An introduction (pp.21-39). London: Routledge.

Hughes, M. (2004). Performance analysis: A 2004 perspective. International Journal of Performance Analysis in Sports, 4(1), 103-109. doi: 10.1080/24748668.2004.11868296

Hurst, M., Loureiro, M., Valongo, B., Laporta, L., Nikolaidis, P., \& Afonso, J. (2016). Systemic mapping of high-level women's volleyball using social network analysis: The case of serve (K0), side-out (KI), side-out transition (KII) and transition (KIII). International Journal of Performance Analysis in Sport, 16(2), 695-710. doi: 10.1080/24748668.2016.11868917

Instruction Manual (2018). Data Volley 4, Data Project.

Laporta, L. (2014). A cobertura de ataque em voleibol de alto nível feminino e masculino. Estruturas e regularidades emergentes do jogo (Unpublished master dissertation). Portugal: Faculty of Sport, University of Porto.

Laporta, L., Afonso, J., \& Mesquita, I. (2018a). The need for weighting indirect connections between game variables: Social network analysis and Eigenvector Centrality applied to high-level men's volleyball. International Journal of Performance Analysis in Sport, 18(6), 1067-1077. doi: 10.1080/24748668.2018.1553094

Laporta, L., Afonso, J., \& Mesquita, I. (2018b). Interaction network analysis of the six game complexes in high-level volleyball through the use of Eigenvector Centrality. PLoS ONE, 13(9), e0203348. doi: 10.1371/journal.pone.0203348

Laporta, L., Afonso, J., Valongo, B., \& Mesquita, I. (2019). Using social network analysis to assess play efficacy according to game patterns: A game-centred approach in high-level men's volleyball. International Journal of Performance Analysis in Sport, 19(5), 866-877. doi: 10.1080/24748668.2019.1669007
Loureiro, M., Hurst, M., Valongo, B., Nikolaidis, P., Laporta, L., \& Afonso, J. (2017). A comprehensive mapping of highlevel men's volleyball gameplay through social network analysis: Analysing serve, side-out, side-out transition and transition. Montenegrin Journal of Sports Science and Medicine, 6(2), 35-41. doi: 10.26773/mjssm.2017.09.005

Marcelino, R., Afonso, J., Moraes, J. C., \& Mesquita, I. (2014). Determinants of attack players in high-level men's volleyball. Kinesiology, 46(2), 234-241.

McLean, S., Salmon, P. M., Gorman, A. D., Stevens, N. J., \& Solomon, C. (2018). Full length article: A social network analysis of the goal scoring passing networks of the 2016 European football championships. Human Movement Science, 57, 400-408.

Mesquita, I., Palao, J. M., Marcelino, R., \& Afonso, J. (2013). Performance analysis in indoor volleyball and beach volleyball. In T. McGarry, P. O Donoghue, \& J. Sampaio (Eds.), Handbook of sports performance analysis (pp. 367379). London: Routledge.

Passos, P., Davids, K., Araújo, D., Paz, N., Minguéns, J., \& Mendes, J. (2011). Networks as a novel tool for studying team ball sports as complex social systems. Journal of Science and Medicine in Sport, 14(2), 170-176.

Paulo, A., Zaal, F. T. J. M., Seifert, L., Fonseca, S., \& Araújo, D. (2018). Predicting volleyball serve-reception at group level. Journal of Sports Sciences, 36(22), 2621-2630. doi:10.1080/ 02640414.2018.1473098

Ribeiro, J., Silva, P., Duarte, R., Davids, K., \& Garganta, J. (2017). Team sports performance analysed through the lens of social network theory: Implications for research and practice. Sports Medicine, 47(9), 1-8. doi: 10.1007/ s40279-017-0695-1

Sasaki, K., Yamamoto, T., Miyao, M., Katsuta, T., \& Kono, I. (2017). Network centrality analysis to determine the tactical leader of a sports team. International Journal of Performance Analysis in Sport, 17(6), 822-831.

Tabachnick, B., \& Fidell, L. (2007). Using multivariate statistics. Boston: Pearson.

Wäsche, H., Dickson, G., Woll, A., \& Brandes, U. (2017). Social network analysis in sport research: An emerging paradigm. European Journal for Sport and Society, 14(2), 138-165. 